\title{
Zimbabwe's Medical Brain Drain: Impact Assessment on Health Service Delivery and Examination of Policy Responses - A Literature Review
}

By

Conrad Chibango ${ }^{1}$

\begin{abstract}
The migration of health professionals to greener pastures negatively impacts on the health service delivery of the source countries. The trend is that doctors and nurses migrate from rural areas to urban areas or from developing countries to developed countries in search of better economic welfare and working conditions. In search of the same conditions, health professionals also migrate from the public sector to the private sector. The causes for this migration, which are largely viewed to be of economic nature, constitute the 'push' and 'pull' factors. It is these factors that policy-makers should carefully study in order to arrest the medical brain drain. Zimbabwe has not been spared of this phenomenon. In the process, the poor, and especially in rural areas, have been the worst victims. Zimbabwean Government policies, though well-intended, have not been adequate enough to arrest the situation. This paper argues that an integrated policy approach is best positioned to address the brain drain problem, which has negatively impacted on the health service delivery system. The integrated policy approach takes cognizance of the various factors that constitute the complex nature of the brain drain. Such factors include global, regional, national, international market labour, development theory and practice, and human rights and justice issues, which, unfortunately, are not usually given much consideration during the policy formulation process.
\end{abstract}

Keywords: brain drain, health service delivery, health professionals, 'push' and 'pull' factors.

\section{Background}

This research is built on the assumption that any society (development countries in particular) needs a healthy workforce in order to achieve its development objectives (World Bank 2004; Clift 2004; Lustig, 2006; MayerFoulkes, 2001). However, the phenomenon of doctors and nurses leaving the country as they head for posts in developed countries is eroding the skilled health workforce base that is needed for economic and social development of the country. The review makes a global and regional overview of the migration of 
health professionals, showing that the phenomenon of losing doctors and nurses to developed countries is not unique to Zimbabwe. However, the main focus shall be on the findings showing the magnitude of the medical brain drain in Zimbabwe, its causes and effects and how the Government of Zimbabwe has responded to the outflow. Instead of only focusing on policies that reverse the medical brain drain, the research also explores other possible policy options, drawing lessons from experiences from other countries in Africa.

\section{Relevance and context of the Study}

The relevance of this study can be looked at from different perspectives. Zimbabwe is represented among the 189 Heads of State and Governments which agreed to the Millennium Development Goals (MDGs) at the United Nations (UN) summit in 2000. Combating HIV/Aids, malaria and other diseases by 2015 is one the three health-related MDGs. However, such a goal will remain outside Zimbabwe's reach if the issue of the continuously dwindling health workforce is not addressed. Article 25 (1) of the Universal Declaration of Human Rights states that "Everyone has the right to a standard of living adequate for the health and well-being of himself and of his family, including...medical care and necessary social services", (WHO/OHCHR, 2007). If Zimbabwe does not have enough health workers to deliver health service, many poor Zimbabweans will not enjoy this right. Following the evidence of developing countries recruiting medical professionals from Southern Africa, some authors have gone to the extent of asking whether such recruitment should not be charged as crime, (Mills et. al, 2008). However, the matter is not that simple because the issue of labour migration triggers debates about globalization, international laws on market labour, right of individuals to migrate, among many others. Some recipient countries and organisations have settled for establishment of ethical codes to prevent recruiting medical professionals from poor countries that are critically in need of health professionals, (e.g. Code of Practice for The International Recruitment of Healthcare Professionals in Scotland Scottish). But the question is whether 'ethical' suffices if it is not legally binding. These issues show that the problem of a medical brain drain is not simply a domestic matter, but has to be addressed within a global context.

\subsection{Description of the Problem}

The health system has three main inputs and these include: human resources, physical capital and consumables. Of the three, human resources are arguably the most important because the performance and delivery of the system largely depends on the knowledge, skills and motivation of those individuals responsible for delivering health services, (Kabene, et. al. 2006). These human resources can also be referred to as human capital. 
For decades, academics and development practitioners have debated about the problem of the flight of human capital. It is also referred to as the brain drain, the loss of highly skilled professionals from a source country to a recipient country and it is used to indicate the flight of the professionals from developing to developed countries, (Sako, 2002).

Since highly skilled professionals in the health sector include many professionals such as pharmacists, laboratory technicians and management, (WHO, 2006), our study shall only focus on doctors and nurses. Thus, in this work, medical brain drain mainly refers to these two categories of health professionals.

Medical brain drain has become one of the contributing factors leading to the continuous deterioration of the health sector of Zimbabwe. Before all this, the health sector of Zimbabwe was considered as one of the best in the African continent. In May 2008, it was alleged that Harare Hospital's neonatal unit was seriously understaffed as nurses and doctors had left for more stable jobs abroad. There was only one radiologist servicing Harare and Parirenyatwa hospitals and the Zimbabwe National Army in May 2008. That radiologist was "borrowed" from the Army. The ratio of doctor to patient was reported to be 1:8000, while the world standard should be 1:500, (Baldauf, 2008).

The World Health Statistics 2007 records show that the health sector in Zimbabwe was critically understaffed, especially for a country whose health situation was already in bad shape. Records show that in 2004, Zimbabwe had a total of 9357 registered nurses and the ratio of nurses to patients was 0.72 per 1000. In 2005, there were a total of 2086 registered physicians (general doctors and specialists) and their ratio to patients was 0.16 per 1000, (World Health Statistics 2007). Zimbabwe faces a challenge of fighting the HIV/AIDS pandemic and malaria disease. The Global Health Facts of 2007 pegged Zimbabwe's HIV and AIDS prevalence rate at 20\%. In 2002, malaria claimed 626 lives and 1.252.668 cases of malaria were recorded, (CIA, 2007). The World Health Statistics 2005 record for expenditure on health per capita was US $\$ 146$, a low budget when compared to the many woes that the country faces. The 2006 estimation of life expectancy was pegged at 44 years for men and 43 for women, (World Health Statistics 2008). It is under these worsening conditions that the country experiences a massive medical brain drain. According to a research carried out in 2006 , about $24 \%$ of Zimbabwean nurses and $51 \%$ of the physicians emigrated, (Clemens, and Pettersson, 2008).

In 2002, a research that included Zimbabwe was carried out by Awases et al. (2004) under the funding of World Health Organisation hinted to the magnitude of the medical brain drain from Zimbabwe. Chikanda (2004) used the 2002 findings to assess the impact of the migration of skilled health workers on Zimbabwe's health sector and to make some policy recommendations. While this 
research focuses on these and other related works, it also considers various policy options that Zimbabwe can adopt in response to the medical brain drain.

\section{Global and Regional Overview of Migration of Health Professionals}

Medical brain drain is not unique to Zimbabwe. Literature shows that it is both a regional and global phenomenon. Many countries in Africa and especially in the region of Sub-Sahara are experiencing medical brain drain but the levels vary from country to country. There are both internal migration and outmigration as health professionals move to other countries within Africa or largely to the developed countries. This shows that the drain is, indeed, a global phenomenon. Most research work shows that there is poor official record keeping of health professionals that migrate to other countries and so it becomes difficult to estimate the magnitude of the migration trends. Studies reveal that there are both 'push' and 'pull' factors of migration, whereby the source country usually loses, while the receiving country gains, (the latter situation is often referred to as 'brain gain'). Policy responses usually tend to foster retention of the skilled health professionals and reverse their migration.

\subsection{Magnitude}

The loss of medical professionals to developed countries is a thing that is experienced by most countries in the Sub-Saharan Africa and the trend appears to be gaining momentum. According to the United Nations Development Program's Human Development Report of 1993, about 21000 Nigerian doctors were practicing in the United States, while Nigeria, the source country, remained understaffed. About 60\% of doctors trained in Ghana in the 1980s had left the country by the end of 2000 . Sudan had a brain drain of $17 \%$ in 1978 . Zambia had only about 400 medical doctors practicing in 2002 only few years after it was reported to have about 1.600 Zambian doctors, (Sako, 2002).

Dovlo and Nyonator (1999) estimated that between 1986 and 1995, 61\% of doctors who qualified from one medical school in Ghana left the country heading for South Africa (6\%), the United Kingdom (55\%) and the United States of America (35\%), (Dovlo (2005).

Labonté, Packer and Klassen, (2006) noted that Canada was a major recipient of foreign-trained health professionals, especially doctors from Africa Sub-Saharan countries and the number of nurses for these countries was gradually increasing. Using destination-country census data to estimate the number of African-born doctors and professional nurses working abroad in a developed country in 2000, and then comparing this to the stocks of these workers in each country of origin, Clemens and Pettersson (2008) found that about 65,000 African-born physicians and 70,000 African-born professional nurses were working overseas in a 
developed country. The findings showed that about $20 \%$ of physicians born in Africa and about $10 \%$ of nurses born in Africa were practicing in developed countries. The situation varied from country to country, depending on the political and economic situation in the various African countries. In Zimbabwe, for instance, where the political situation had been unstable since 2000, the study shows that $51 \%$ of the Zimbabwean physicians and $24 \%$ of Zimbabwean nurses were estimated to be working elsewhere in the world, (Clemens and Pettersson, 2008). The table below was adapted from Nullis-Kapp (2005) and it shows the trend of the migration of Zimbabwean nurses to the United Kingdom. There were 52 Zimbabwean nurses that applied to be registered in the United Kingdom. In $1999 / 2000$ the number had risen to 221 and the figure was 391 by 2003/2004.

Table: Number of Zimbabwean nurses who applied for registration in the UK.

\begin{tabular}{|l|l|l|l|l|l|l|}
\hline Year & $1998 / 99$ & $1999 / 2000$ & $2000 / 01$ & $2001 / 02$ & $2002 / 03$ & $2003 / 04$ \\
\hline Number & 52 & 221 & 382 & 473 & 485 & 391 \\
\hline
\end{tabular}

\section{'Push' and 'Pull' Factors}

The migration of skilled health workers from developing countries to developed countries is a result of several factors that can be summarized as 'push' and 'pull' factors and its frequency follows a particular pattern.

According to the International Council of Nurses (2001), the pattern of migration tends to flow from rural to urban, from lower income areas to the more affluent, and then from the developing to the developed countries. Health workers also tend to move from the public sector to the private sector in the health service as well as from the public sector to the private commercial sector such as pharmaceuticals.

The 'push' factors of migration vary. The International Council of Nurses (ICN) consider the desire for more professional development opportunities, better salaries and living conditions as the causes of migration, (ICN, 2001 in Awases et al., 2004). Sako (2002) argues that brain drain in Africa is severe due to unfavourable political and economic conditions and these need to be addressed. In a study carried out in Ghana, poor health care infrastructure, low salaries, family pressures and a desire for better living standards and poor staff management were cited as 'push' factors, while 'pull' or attracting factors in the destination country included higher salaries, better training and career opportunities, better health infrastructure and resources, among others, (Sagoe, 2007).

Salary may remain as a 'pull' factor for a long time, owing to the huge disparity between the salaries offered in the source countries and those offered in the destination countries. A study by Vujicic et al. (2004) showed that purchase parity 
physician wages in the USA were 22 times those in Ghana and about 4 times those of South Africa. Wages of nurses in Australia and Canada were 14 times those in Ghana and 25 times those of Zambia and about twice those of South Africa, (The JLI Africa Working Group, 2006).

\subsection{Effects}

Whether the migration of doctors and nurses yields positive or negative impacts on the health sector of the sending country is subject to debate. Though in countries like Philippines where doctors and nurses are, as it were, 'trained for export' to the developed countries in order to gain remittances, exchange ideas and to acquire new skills, the impact on Africa is usually argued to be more negative than positive.

The Africa Working Group (2006) argues that the loss of skilled health professionals and researchers creates serious problems in ensuring the future training and supply of quality health workers and also the impact on the quality of care provided. The health professionals that remain are faced with heavy workloads due to shortage and poor workforce management and this increases the frustrations of those health workers. These factors then serve as a further push to migration (The Africa Working Group, 2006), turning the whole scenario into a vicious circle.

Medical brain drain could be viewed from two different angles. On the one hand, it can be described as the 'looting' of health professionals from poor countries by rich countries. On the other hand, some consider the opportunities it creates for the for the source country. Using Malawi as a case study, Record and Mohiddin (2006) debate that there are potential gains in managing medical migration to produce outcomes that benefit both the individual households and the source country. However, estimating the cost of training a general practice at US\$60,000, The African Union (2003) concludes that low-income developing countries 'subsidize' developed countries by US\$500 million annually. UNECA (2000) also estimated that Africa might have lost about US $\$ 1.2$ billion from the 60,000 professionals lost between 1985 and 1990 alone, (The Africa Working Group, 2006).

\subsection{Policy Responses}

Most developing countries have responded by establishing policies that encourage retention of critical professionals such as doctors, nurses, pharmacists, laboratory technologists and physiotherapists. The 'push' and 'pull' factors are studied in order to find appropriate measures to stem the medical brain drain. The negative impact on the source countries caused by migration of health workers poses ethical dilemma. Would it be proper for source countries to restrict migration, thus taking away the right of workers to emigrate? The bottom 
line is: the migration needs to be regulated. Some countries such as the United Kingdom have introduced voluntary Codes of Practice (COP) for the ethical recruitment of international health workers in order to protect the rights of migrant workers and support them in their job. The United Kingdom COP discourages the National Health Service from actively recruiting from the developing countries either directly or through private recruitment agencies.

It has been observed, however, that the impact of the United Kingdom COP and other similar strategies has been limited because these codes are not legally binding and do not cover all employees working in the private sector including private hospitals and nursing homes. In addition, the increasing needs in the developed countries due to low population growth, reduced number of young people to join the health profession is an indicator that most of these countries may continue to actively recruit professionals from developing countries, (The JLI Africa Working Group, 2006; J. Buchan et al. 2006).

Mensah et al. (2005) argue that there is no way any code of ethics can reverse the level of international labour market integration. This being the case, the authors argue that international labour market integration in health care are currently accruing chiefly to the advantaged among health service users, namely, the developed countries. Therefore, they suggest that policy responses should directly address reconstruction of health service in the source countries. However, the JLI Africa Working Group (2006) does not stop there; it moves the motion that a key action should be taken to ensure a total compensation package.

\section{National Overview of Migration of Health Professionals Literature}

Several works have been done already concerning Zimbabwean health professionals and migration but from different angles (Awases et al., 2004). Some literature focuses on internal migration, (Mutambirwa, 1990 and Potts, 1995) and others on migration of skilled workers from the country, (Gaidzanwa, 1999). There is also literature that focuses on the impact of health sector reform on the motivation of health professionals, (Mutizwa-Mangiza, 1996; Republic of Zimbabwe, 1999; Ndlovu et al., 2001). More works include that of Gelfand (1998) on health profession during the colonial era, Mutizwa-Mangiza (1998), whose work reveals a trend of health professionals leaving the public sector and Stilwell (2001), who suggests that departure from the public sector is caused by the challenges that come with the continuous handling of several HIV/AIDSrelated deaths, poor working conditions and low salaries, (Awases et al., 2004). Awases et al., (2004) in a survey carried out in 2002, look at the migration of health professionals in six countries (Cameroon, Ghana, Senegal, South Africa and Uganda) between 1991 and 2000. The research revealed that even though there was an increase in the number of state-registered health professionals, there 
was a migration pattern of the professionals moving from rural areas to urban areas and from public sector to private sector. This movement is found to disadvantage the poor who cannot afford private health services. Economicrelated reasons were given as a common 'push' factor for migration. The research highlights that the migration of skilled health professionals has yielded a negative impact on the health sector in Africa as a whole. It calls for African governments to address this issue and suggests that all countries adopt the Commonwealth Code of Practice for International Recruitment, among many other policy options that can be established.

Using the findings of Awases et al., (2004) on Zimbabwe, Chikanda (2004) explores the magnitude of the migration of skilled health professionals and then assesses its impact on health service delivery. In his paper published by the Centre on Migration, Policy and Society, Chikanda identifies the main 'push' and 'pull' factors leading to both internal and out-migration of skilled health professionals. The work shows that poor working conditions, low salaries and political unrest are the main causes for health professionals' migration in Zimbabwe. He ends his paper by making some policy recommendations, which we shall further discuss below. In 2005, Chikanda made a more detailed analysis of the same findings of Awases et al., (2004) and pointed out that the migration trends and effects would not change unless they were urgently addressed.

Although they do not address skilled health workers in particular, some studies on migration of both skilled and potentially skilled professionals in Zimbabwe (Tevera and Crush, 2001; Tevera and Zinyama, 2002; Tevera, 2005) help to highlight the possible causes and effects of skilled health professionals' migration and the impact it has on the health sector.

We now take a closer look at the magnitude, 'push' and 'pull' factors and effects of migration of doctors and nurses in Zimbabwe as highlighted in the research carried out in 2002 by Awases et at., (2004) and as assessed by Chikanda (2004 and 2005). The overview below is mainly based on the assessment made in Chikanda (2004).

\subsection{Methodology}

Various methods were used in the study (by 'study' we refer to Awases et at., 2004) and these included a representative survey of health professionals in Zimbabwe, focus groups and interviewing of key informants and individual health workers from the Ministry of Health and Child Welfare (MoHCW). Community users of the health system, migrant and returnee health staff were also interviewed. The study did not manage to interview professionals outside the country. Incomplete data on skilled professionals working in the various institutions was also another limitation, (Chikanda, 2004). 


\subsection{Magnitude and Pattern of the Migration}

The analysis of data collected at national level indicates the trends of migration of doctors and nurses in the country. Data from the Central Statistics Office covering a period of four years (1995-1998) show that even though a total of 100 doctors were trained every year, the fact that the number of doctors increased by only 51 during the same period probably shows the extent to which international migration was occurring. The drop in the number of nurses is even alarming. While in 1998 there were a total of 15,476 nurses registered nationally, only 12,477 remained registered by December 2001 .

The study showed a crisis in the public sector as doctors and nurses moved from the public sector to the private sector, while some left for overseas, namely, the United Kingdom. For instance, while the public sector had a total of 8662 in 1996, by 1999, the number had dropped to 7007; a difference of about 1000 , regardless of the fact that there were 300 nurses produced every year. In 1997, only $33.7 \%$ of the doctors registered in the country were employed in the public sector and most of the remainder worked in the private sector.

Workloads of doctors and nurses that did not migrate increased. The MoHCW estimated the (2004) doctor rate to patient at 1:6000 and that of nurse to patient at 1:700. However, these rates would vary according to the location of the health institutions. Hospitals in urban areas had more staff than those located in rural areas. Likewise, provincial hospitals were better staffed than the district ones. Doctors working at district hospitals had heavier workloads than those at provincial and central hospitals where there were more doctors and an option for patients to go to the private sector.

'Push' and 'Pull' Factors

About $68 \%$ of health professionals interviewed expressed intention to migrate and work in other countries, mostly in the United Kingdom, South Africa and Botswana. Reasons given for intention to migrate had to do with the economic hardships they were going through. Some of the health professionals that considered emigrating sought better salaries in the intended countries of destination, money to buy a car or a house, while others sought better living conditions as they could not see any future in Zimbabwe. Some of the reasons given for emigration included increased political violence in the country, securing a future for the children, lack of resources and facilities in the country, a general decline of health care services and poor management of those services in the country.

The study also showed that most health professionals (87\%) were not happy with the salaries offered in the public sector and some $(68.5 \%)$ could not live on their earnings. Some $(86.6 \%)$ saw it necessary to take two or more jobs as a copying strategy and others $(67.5 \%)$ intended to move to the public sector, which was viewed (by $77.9 \%$ ) as offering better fringe benefits than the public sector. 
The study showed that the prevalence of HIV/AIDS together with insufficient facilities to prevent possible infection during work created stressful working conditions due to fear of contracting the virus. The disease also increased the workload of the nurses and doctors and some of them (58.4\%) found it stressful to care for HIV/AIDS patients. However, $76.2 \%$ were still willing to exploit their medical skills in the face of all the challenges posed by HIV/AIDS.

\subsection{Effects of Migration on Service Delivery}

Medical brain drain has made a negative impact on the health sector. The remaining staff had excessive workloads and this led to low morale. It meant dealing with many patients, who in turn had to wait for long hours in order to be attended to. There were also some unnecessary deaths as some patients died of otherwise curable diseases while waiting in long queues. Migration swept away most of the experienced professionals and this compromised the quality of work. The drain has also caused inequity in terms of access to health delivery services. The rural areas were affected most as most skilled health professionals moved to urban areas. Unqualified cadres filled the created gap in the rural areas and this compromised the quality of service delivery. It was observed in the study that some patients turned to the informal health sector, particularly the traditional healers who charged affordable fees. However, these could not be relied on since some were only after money as they lured clients by falsely claiming to cure HIV/AIDS.

\subsection{Factors influencing the Retention of Health Professionals}

The study showed that many professionals would stay if they were offered better salaries $(76.6 \%)$, better fringe benefits $(71.4 \%)$ and a more pleasant and caring working environment (69.3\%). Many (59.7\%) intended to stay if there were improved facilities and resources in the health care system and a reasonable workload. A more peaceful social environment in the country motivated some $(51.5 \%)$. Others $(50.6 \%)$ intended to stay if there were more accessible education and training opportunities. Some of the motivating factors included better working relationships in the public health sector, better quality education and training in respective professional fields, provision of adequate day care facilities for children of employees and better leadership in the health sector among many others. Most health professionals (83.3\%) indicated that better salaries would lure the health professionals back to their country of origin. Some $(58.3 \%)$ indicated better incentives as a major 'pull' factor for doctors and nurses abroad.

\subsection{Policy Responses}

In response to the medical brain drain, the Zimbabwean Government went into agreement with the Cuban Government in 2002 and managed to bring 
117 Cuban doctors into the country but these were to work on a short-term contract basis. While this eased the shortage, it was felt that the relief was only temporary due to the nature of the contract and language barriers which negatively affected teamwork.

The Government also introduced several policies in order to improve the public health sector but these yielded mixed results. It provided housing and transport allowances. It also increased salaries. This helped to reduce the outflow of health professionals from the public health sector. Call and stand-by allowances were introduced but health professionals complained of unpaid allowances and the policy that stand-by allowances should not be higher than the salary did not please them since in some cases, especially in the rural areas, call and stand-by hours exceeded the normal working hours. In order to reduce migration of health professionals motivated by the need for further studies, the Government introduced fellowship and scholarship programmes and advanced training programmes in order to build the capacity of the health professionals in their respective fields. A bonding policy for newly trained doctors and nurses was also introduced to reinforce retention.

The study showed that communities were not doing much to retain their health staff. Results from community respondents revealed that they believed it to be the role of the Government to establish lasting measures to retain staff in the rural areas. Some complained that they were not consulted - hence they felt eliminated from the decision making process concerning the health delivery services in their areas.

The 2002 research by Awases et al. showed that migration of health professionals had a negative impact on health service delivery in Zimbabwe and most affected were the rural areas where the majority of Zimbabweans stays. Migration from public sector to private sector appeared to be the major reason leading to the collapse of the former. The number of health professionals employed at national level was declining even though some were joining the private sector. This indicated that health professionals joined the private sector in order to raise funds to go overseas.

Since the major obstacle faced during the study was the lack of quantitative data, Chikanda (2004) suggests that both government health institutions and MoHCW should nurture a habit of keeping records of health professionals. This is important because it facilitates the formulation of policies that are informed by reliable data. Given that the study revealed economic factors as major reasons for the migration of doctors and nurses, Chikanda recommends the Government to address the issue of remuneration of health professionals with urgency in order to curb the migration trend and to address the complaints of the professionals without confrontation. 


\section{The Need for integrated policy options}

The phenomenon of medical brain drain is complex in nature as it is characterized by, not only local, national, international and global factors, but also by other factors such as the development approaches, human rights and justice issues. An international perspective, for instance, takes cognizance of the fact that the problem of medical brain drain is not unique to Zimbabwe alone. It is also experienced by other developing countries in Africa and elsewhere in the world. As a result, though policies may focus on the internal factors that negatively affect health service delivery; these challenges are strongly influenced by the global, regional and national policy environments. The Zimbabwean Government may increase salaries to the satisfaction of the health professionals but an international organization involved in active recruitment of these professionals may also respond by offering unbeatable salaries that further motivate skilled health professionals to migrate. In this way, the solution to this issue cannot be solely domestic. Besides national policies, there should also be regional and international policies that go beyond ethical codes. Hence; an integrated policy approach whereby global, regional, national, international market labour, development, and human rights and justice issues are taken into consideration is, therefore, best suited to adequately address the problem of brain drain.

In the global context, neoliberal policies which call for the opening up of borders to give access to free trade can also be interrogated in the medical brain drain debate. Poor countries lose because they cannot compete with the developed countries in paying their own skilled professionals; world-standard products of the colleges they sacrificed to fund. It is not in our interest to explore the impacts of neoliberal policies in this paper, but to discuss options for policy formulation. From an international perspective, Dovlo (2007) suggests that a comprehensive and respected international framework is required to moderate losses of critical health workers and devise ways of reducing the negative effects it has on poor communities. At country level, Dovlo gives an example of Norway whose international recruitment approach is based on inter-country agreements covering both private and public sectors and is managed by a single government unit.

Just as it entered an agreement with Cuba and managed to bring Cuban doctors into the country, the Zimbabwean Government can also regulate the migration of its health profession by entering an agreement with a country destination such as the United Kingdom and South Africa, where most of its professionals end up practising. In this way, Government may partly recover the cost of training it invested in the migrant health professionals and use the remittances to reinvest into the health sector. However, without a national database of health professionals and a good record keeping in health institutions, (Chikanda, 2004), 
such an initiative may not be manageable. Allegorically put, you cannot claim to have lost some of your money if you do not know how much you had in the first place. The Government cannot, for instance, claim reparation/compensation from receiving countries if it has no proper records.

Zimbabwe can also learn from its counterparts in Sub-Saharan Africa that have come up with innovative initiatives to achieve quick results in ensuring delivery of health services to the poor majority. In order to urgently increase their workforce of trained health providers, some African countries considered introducing new types of workers. Ethiopia came up with the concept of 'Health Extension Workers', while Ghana introduced 'Community Health Officers/Nurses'. These are midlevel workers that would need supervision and integration with professional-level providers (Dovlo, 2007) and this would inevitably have its own challenges. Mozambique introduced a 'surgical technicians' programme which saw the training of mid-level health service providers who are now a significant component of the health workforce, (The JLI Africa Working Group, 2006). However, these case studies need to be investigated further before they can be adopted and tailored according to the Zimbabwean health delivery setting.

There is increasing consensus in development theory and practice that development interventions should encourage the participation of beneficiaries in the decision making process, (Chambers, 1997). The study by Awases et al. (2004) showed that the poor recipients of the public health services complained that decisions were just passed down to them without their consultation. To avoid negative unexpected outcomes, the Government should to create some democratic space at community level or ensure that the available structures are used by the poor to express their views on health matters. This bottom-up approach, whereby views of the beneficiaries are taken seriously, will help stimulate the poor people to be actively involved in issues concerning health in their communities as well as reduce the gap between them and the health professionals. Involving the community can be one way of promoting retention of health professionals in rural areas.

\section{Conclusion}

This review has shown that the migration of doctors and nurses has yielded negative effects in health service delivery in Zimbabwe. A large portion of doctors and nurses has deserted the public health sector on which many poor people depend, and has moved to the private sector and other countries. The gap created meant extra workload for the remaining staff and it is the rural people that have been worst affected. Doctors and nurses have migrated due to 'push' and 'pull' factors and it is these factors that need to be addressed in order to stem 
the medical brain drain. The Government's policy response has not been effective enough to retain the professionals. Given the fact that the migration of health professions is not only a domestic but also a multi-lateral phenomenon with global economic, international and regional factors among others, this paper has argued that an integrated policy approach is best suited for providing a longterm solution to Zimbabwe's medical brain drain.

\section{References}

AWASES, M., A. GBARY, J. NYONI and R. CHATORA, 2004. Migration of health professionals in six countries: a synthesis report, Brazzaville: WHO.

BALDAUF, S, 2008. Inside Zimbabwe's Health Crisis, in The Christian Science Monitor, 30 May 2008 edition.

BATATA, A, S, 2005. International nurse recruitment and NHS vacancies: A cross-sectional analysis in Globalization and Health, 1(7).

BUCHAN, J., I. SECCOMBE and R. HUT'T, 2006. Nurse Migration and The Commonwealth Interim Report, The Commonwealth Secretariat/Royal College of Nursing.

CHAMBERS, R, 1997. Whose Reality counts? Putting the First Last, London: Intermediate Technology Publications.

CHIKANDA, A, 2004. Skilled health professionals' migration and its impact on health delivery in Zimbabwe, in Centre on Migration, Policy and Society Working Paper No. 4 University of Oxford.

CHIKANDA, A, 2005. Medical leave: The Exodus of Health Professionals from Zimbabwe, Southern African Migration Project.

CIA, The World Fact Book 2007, http://www.cia.gov/cia/publications/factbook.

CLEMENS, M, A, and G. PETTERSSON, 2008. New data on African health professionals abroad in Human Resources for Health, 6(1).

CLIFT, J, (ed). 2004. Health and Development: A Compilation of Articles from Finance and Development, Washington D.C: International Monetary Fund.

DOVLO, D, 2007. Migration of Nurses from Sub-Saharan Africa: A Review of Issues and Challenges, HSR: Health Services Research 42(3).

DOVLO, D, 2005. Wastage in the health workforce: some perspectives from African

Countries in Human Resources for Health, 3(6).

LABONTÉ, R., C. PACKER and N. KLASSEN, 2006. Managing Health Professional Migration from Sub-Saharan Africa to Canada: A Stakeholder Inquiry into Policy Options, in Human Resources for Health, 4(22).

LUSTIG, N, 2006. Investing in Health for Economic Development: Case of Mexico, Research Paper No. 2006/30, UNU-WIDER.

KABENE, S, M., C. ORCHARD, J. M. HOWARD, M. A. SORIANO AND R. LEDUC, 2006 The importance of Human Resources Management in Health Care: a Global Context, in Human Resources for Health, 4(20).

MAYER-FOULKES, D, 2001. "The Long-Term Impact of Health on Economic Growth in Mexico, 1950-1995”. In Journal of International Development 13(1): 123-6.

MENSAH, K., M. MAUREEN and L. HENRY, 2005. The 'Skills Drain' of Health Professionals from the Developing World: A Framework for Policy Formulation. 
MILLS, E. J., W. A. SCHABAS, J. VOLMINK, R. WALKER, N. FORD, E. KATABIRA, A. ANEMA, M. JOFFRES, P. CAHN and J. MONTANER, 2008. Should Active Recruitment of Health Workers from Sub-Saharan Africa be Viewed as a Crime? in Viewpoint, 371, www.thelancet.com

NULLIS-KAPP, C, 2005. Efforts Underway to Stem 'Brain Drain' of Doctors and Nurses, in Bulletin of the World Health Organisation, 83(2), 84-85.

RECORD, R and A. MOHIDDIN, An economic perspective on Malawi's medical "brain drain" in Globalization and Health 2006, 2(12).

SAKO, S, 2002. Brain Drain and Africa's Development: A Reflection, in African Issues, 30(1), 25 30.

SCOTTISH EXECUTIVE, 2006. Code of Practice for The International Recruitment of Healthcare Professionals in Scotland, Edinburgh.

TEVERA, D. S, 2005. Early departures: The Emigration Potential of Zimbabwean Students, Southern African Migration Project.

TEVERA, D. S. and J. CRUSH, 2003. The new brain drain from Zimbabwe: Investing the causes behind skilled migration in Zimbabwe, Southern African Migration Project.

TEVERA, D. S, and L. ZINYAMA, 2002. Zimbabweans Who Move: Perspectives on International Migration in Zimbabwe, Southern African Migration Project.

THE JLI AFRICA WORKING GROUP, 2006: The Health Workforce in Africa: Challenges and Prospects.

WHO/OHCHR, 2007. The Right to Health, in Joint Fact Sheet, 323.

WORLD BANK, 2004. World Millennium Development Goals for Health: Rising to the Challenges, Washington DC: World Bank.

WORLD HEALTH STATISTICS, 2007. WHOSIS (WHO Statistical Information System). http://www.who.int/whosis/whostat2007/en/index.html

WORLD HEALTH STATISTICS, 2008. Zimbabwe Health Statistics 
